Portland State University

PDXScholar

Summer 2013

\title{
A Community-Based Wellness Program to Reduce Depression in African Americans: Results From a Pilot Intervention
}

\author{
Christina Nicolaidis \\ Portland State University \\ Corliss McKeever \\ African American Health Coalition, Inc. \\ Sandra Meucci \\ African American Health Coalition, Inc.
}

Follow this and additional works at: https://pdxscholar.library.pdx.edu/socwork_fac

Part of the Community Health Commons, Psychiatric and Mental Health Commons, and the Public Health Commons

Let us know how access to this document benefits you.

\begin{abstract}
Citation Details
Nicolaidis, C., McKeever, C., \& Meucci, S. (2013). A Community-Based Wellness Program to Reduce Depression in African-Americans: results from a pilot-intervention. Progress in community health partnerships: research, education, and action, 7(2), 145.
\end{abstract}

This Article is brought to you for free and open access. It has been accepted for inclusion in Social Work Faculty Publications and Presentations by an authorized administrator of PDXScholar. Please contact us if we can make this document more accessible: pdxscholar@pdx.edu. 


\title{
A Community-Based Wellness Program to Reduce Depression in African Americans: Results From a Pilot Intervention
}

\author{
Christina Nicolaidis, $\mathrm{MD}, \mathrm{MPH}^{1}$, Corliss McKeever, $\mathrm{MSW}^{2}$, Sandra Meucci, $\mathrm{PhD}^{2}$ \\ (1) Departments of Medicine and Public Health \& Preventive Medicine, Oregon Health \& Science University; (2) African American Health Coalition, Inc. \\ Submitted 19 January 2012, revised 17 August 2012, accepted 14 October 2012. This study was funded by the African American Health Coalition, Inc. A portion of \\ Dr. Nicolaidis's time was supported via a grant from the National Institute of Mental Health (K23MH073008).
}

\section{Abstract}

Background: African Americans are less likely than nonHispanic Whites to find antidepressants acceptable or seek care for depression.

Objective: To develop and pilot test a culturally tailored, community-based, psychoeducational wellness and exercise promotion program to reduce depressive symptoms in African Americans.

Methods: Participants were African Americans with moderate depressive symptoms who were interested in exercise but were not exercising regularly. They attended a 6-week psychoeducational group program during which they set personal activity goals and learned depression self-management skills. We conducted pre- and postintervention surveys and postintervention feedback sessions.

Results: Twenty-one African Americans participated in the intervention. The program had excellent attendance and satisfaction. We found a large reduction in depressive symptoms, with mean Patient Health Questionnaire-9 (PHQ-9) scores dropping from 14.8 to $7.1(p<.0001)$, and increases in exercise and depression self-efficacy and behaviors.

Conclusions: This pilot study offers promising preliminary evidence to inform further research on the use of community-based, culturally tailored wellness programs to address depression.

\section{Keywords}

Depression, exercise, African Americans, communitybased programs, health promotion, community-based participatory research, culturally tailored interventions, self-management
A frican Americans with major depressive disorder (MDD) are significantly less likely than non-Latino Whites to receive guideline-appropriate depression care, take antidepressants, or receive any depression care, even after adjustment for insurance status and socioeconomic factors. ${ }^{1,2}$ Part of the disparity in depression care is likely due to African Americans' mistrust of the healthcare system and lower acceptance of antidepressant medications. African Americans are less likely than non-Latino Whites to seek specialty mental health care, accept recommendations to take antidepressants, or find counseling an acceptable option., ${ }^{3,4}$ Another part of the disparity may be due to cultural messages valuing strength and stigmatizing depression. ${ }^{5}$

In the Pacific Northwest, African Americans face additional challenges because of the relative lack of racial diversity. Whereas African Americans make up $12.8 \%$ of the U.S. population, they comprise only $1.8 \%$ of the population in Oregon. ${ }^{6}$ As such, there are few culturally specific services and resources. With only a handful of African American physicians or therapists in the whole state, most African Americans must seek mental health care from non-racially concordant providers, many of whom have little experience in caring for African American patients and little training in cultural competency. In our prior focus group study of 
depressed African American women in Portland, Oregon, participants viewed the healthcare system as a "White system" and expressed very negative attitudes toward antidepressant medications. They were particularly interested in depression care strategies to self-manage their symptoms, but they often did not have the skills and tools needed to effectively implement such strategies.

The African American Health Coalition is a local community-based, nonprofit organization that has been promoting health and improving wellness in African Americans through health education, advocacy, and research for more than 20 years. One of their programs allows African Americans to receive access to local exercise facilities. This program has been found to be effective in increasing activity in African Americans with cardiovascular disease. ${ }^{8}$

A growing literature supports the effectiveness of exercise in reducing depressive symptoms. ${ }^{9}$ Given the community's concerns about antidepressants, the lack of culturally specific mental health services, and the desire for self-management strategies, exercise may be a particularly appealing approach to managing depressive symptoms for some African Americans. However, most research on exercise for the treatment of depression is with White participants and uses highly structured, supervised exercise programs that are not likely to be reproduced in real-world settings. African American Health Coalition leaders were concerned that participants with depressive symptoms may need additional support to manage their depression and to initiate and maintain a realistic health promotion program. Thus, they decided to partner with an academic investigator to develop and pilot test a community-based, culturally tailored psychoeducational wellness program focused on increasing physical activity and depression self-management behaviors in African Americans with symptoms of MDD.

\section{METHODS}

\section{Community-Academic Partnership}

The President/CEO of an African American communitybased organization, who herself is a masters-level clinical social worker and certified master trainer in chronic illness self-management, ${ }^{10}$ approached a physician-researcher at a local university to collaborate on this project. The two women co-led the project as the community and academic Principal Investigators (PIs), respectively. The community PI and community Co-Investigator (Co-I) designed the intervention and recruited participants. The academic PI, the community PI and the community Co-I jointly decided on evaluation methods and created study protocols and recruitment, consent, and data collection instruments. The community PI led intervention sessions and the community Co-I collected data from participants. The academic PI led the data analysis and the three women collaboratively interpreted results and co-authored this paper. The study was approved by the university's institutional review board.

\section{Setting, Recruitment, and Eligibility}

The intervention was set within the African American Health Coalition's existing exercise card program, which offers African American adults a pass to use selected community exercise facilities at a greatly reduced cost. Participants complete an intake questionnaire with questions about their exercise habits, medical diagnoses, and medications, as well as the Depression Scale of the PHQ-9. ${ }^{11-13}$

To be eligible for the intervention, participants had to be 18 years of age, African American or of African descent, experiencing moderate depressive symptoms, as indicated by a score of 10 to 20 on the PHQ- $9,{ }^{11}$ and exercising fewer than three times per week, for a minimum of 30 minutes per session, over the past month. The community PI or Co-I called current program participants who scored between 10 and 20 on the PHQ- 9 when they enrolled in the exercise card program, asked questions about their exercise habits to assess eligibility, and invited participants to the intervention. They started with participants who had most recently completed the intake questionnaire and stopped inviting participants when participation targets for the pilot intervention were met. Participants completed in-person informed consent at the first group meeting.

\section{The Pilot Intervention}

The community PI and Co-I created the intervention, using concepts and materials from several sources. As certified trainers in the Stanford Patient Education Center Chronic Disease Self-Management Program, ${ }^{10}$ they incorporated basic concepts of chronic illness self-management and 
Action Planning from the Chronic Disease Self-Management Program, as well as specific patient handouts from its associated workbook. The Chronic Disease Self-Management Program is a workshop series for people with a variety of different chronic diseases. It teaches the skills needed in the day-to-day management of chronic disease and to maintain and/or increase life's activities.

They added specific information about depression and depression treatment using materials the academic PI had developed for the Interconnections Project, a communitybased depression care program for African American abuse survivors. ${ }^{14}$ They also added suggestions for healthy eating from The New Soul Food Cookbook for People with Diabetes. ${ }^{15}$ Every session was targeted to African Americans, with, for example, open discussions of the impact of their everyday experience of racism and the cumulative effect of carrying this stress, and discussions of cultural barriers to treatment.

The intervention consisted of six weekly 2 -hour sessions. Table 1 summarizes weekly topics, activities and handouts. The Community PI began sessions with a brief didactic presentation using PowerPoint slides created for this intervention, and then facilitated a discussion, ensuring participation by all group members. The entire group then participated in Action Planning for setting weekly goals and checking on their progress in achieving these goals. Considerable attention was paid to setting realistic weekly goals, specifying time, frequency, and location of intended activities. Each participant also assessed their level of confidence in their likelihood of

Table 1. Outline of Weekly Topics, Activities, and Materials Distributed

Week Topics Handouts

1 Purpose of Study; Why Depression; What Form dyads for discussion about "What is Is Depression; Myths about Depression; Cultural Barriers to Treatment for Depression

2 Relationship of Exercise to Depression; Benefits of Fitness; Self-management; Action Planning; Barriers to Action Planning; Self-Commitment

Dealing with Stress and the Stress from Racism; Negative Self-Talk; Positive Self-Talk; Self-Efficacy; Visualization; Guided Self-Imagery; Progressive Muscle Relaxation

Recognizing When We Are Depressed; Causes of Depression; Situations Causing Depression; Steps in Managing Depression; How Relationships impact Depression

5 Healthy Eating - What is it? The Soul Food Healthy Cooking Movement; Examples of Recipes from Soul Food Cookbook

Dyads: Share with partner the physical activity goal setting; Schedule exercise date
6 Putting it all Together; How to Maintain Self-Management of Depression depression”; Report back to group

Individuals name health improvement they want to make; Goal setting exercise specifying what, how much, when, and how often

\section{- Discussion on changes related to food preparation, shopping, portion sizes; recipes}

- Dyads to Check-in on Action Plan from previous week

Pretests; Consent Waivers; Signs and Symptoms of Depression; Myths about Depression

Effects of Exercise on Depression; Kinds of Physical Activities; What are Your Exercise Barriers; Parts of an Action Plan; Self -Management Tool Kit

Progressive Muscle Relaxation; Guided Imagery

- State your name and your action plan from last week

- Did you accomplish the plan?

-If not, what barriers did you encounter?

- Do you have ideas how to overcome those?

-Do you want suggestions from the group?

Discussion of causes of depression for each individual; Action Planning on managing depression; Check in on Action Plan from Previous Week

Causes of Depression; Sleep Problems

A Formula for a Healthy Meal; Nutrition Facts to Look for on Food Labels; Diabetes; Heart Disease; Managing a Healthy Weight; Food-Mood Diary

Post-tests 
accomplishing the goal, and revised the goal if their confidence level was not high. Although there were not actual exercise movements demonstrated or conducted as part of the session, members were encouraged to set goals related to exercise and to adopt a buddy system for using community exercise facilities as part of their normal weekly routines, unsupervised by project staff. Participants were divided into two groups that met on different days of the week. Each group included 8 to 14 participants who met weekly for 2 hours over 6 weeks.

\section{Data Collection and Measurement Instruments}

Participants completed written pre- and postintervention surveys administered at the first and last sessions and participated in one of two group open-ended feedback sessions. Feedback sessions directly followed the last session, were led by the community Co-I, lasted 1.5 hours, and were taperecorded and transcribed. Participants received $\$ 20$ gift cards for participating in the pre- or postintervention assessments.

Our primary outcome was change in depression severity, as measured by the Depression Scale of the PHQ-9. ${ }^{11-13}$ A meta-analysis of 14 studies found that a cutoff of 10 on the PHQ-9 had a sensitivity and specificity for MDD of 0.80 and 0.92 , respectively. ${ }^{16}$ The PHQ-9 has been found to reliably track change in severity of depressive symptoms over time. ${ }^{17}$

We also assessed a number of intermediate outcomes related to depression and exercise. We measured self-efficacy related to depression care using a six-item scale ${ }^{18}$ and assessed five depression self-management behaviors. ${ }^{18}$ We also measured exercise self-efficacy using a six-item scale ${ }^{19}$ and stage of exercise behavior change using a single item. ${ }^{20}$

We measured perceived effectiveness of our intervention using six de novo items on the postintervention survey. Response options used a 5-point Likert scale with anchors of very effective/very ineffective. We measured overall satisfaction with a single item. Response options used a 5-point Likert scale with anchors of very satisfied/very dissatisfied. We also collected information on demographic characteristics, insurance status, and healthcare utilization.

\section{Data Analysis}

We used descriptive statistics to analyze participants' ratings of the program and attendance. We compared pre- and postintervention outcomes using a paired $t$-test for continu- ous outcomes and the test of symmetry/McNemar's test for categorical or dichotomous outcomes. The academic PI and community Co-I independently analyzed transcripts from feedback sessions, using the technique of thematic analysis, ${ }^{21}$ with an inductive approach, and then jointly decided on common themes. They specifically looked for themes about how participants felt the program impacted them, what they thought was helpful, and what they would recommend changing. ${ }^{21}$

\section{RESULTS}

While signing up for an exercise card, 2,849 African Americans completed an intake form. Fourteen percent screened positive for MDD with a PHQ-9 score of 10 or higher. Of those who screened positive, only $42 \%$ reported a known diagnosis of depression, and only $25 \%$ reported use of antidepressant medications.

We invited 35 people to the program, 22 of whom (63\%) consented to participate. Nineteen participants (86\%) completed both the pre- and postintervention assessments and participated in the feedback sessions. Participant ages ranged from 20 to 66 years (mean, 40.6). All but one participant were female. There was a broad range of household incomes, with one quarter of participants noting annual incomes below $\$ 15,000$ and one third noting incomes over $\$ 40,000$. Obesity was very prevalent amongst participants, with a mean body mass index of $36 \mathrm{~kg} / \mathrm{m}^{2}$. A minority of participants had received any care for depression over the past 6 months (Table 2).

The program had excellent attendance, with $86 \%$ attending at least five of the six sessions. All participants (100\%) were satisfied with the program and $95 \%$ answered that the program was very effective (Table 3 ).

We found a very large, significant reduction in depressive symptoms, with mean PHQ-9 depression scores dropping from 14.8 to $7.1(p<.0001)$. There were also increases in participants' depression and exercise self-efficacy scores, their use of depression-related self-management behaviors, and their physical activity stage (Table 4). Only one participant started using antidepressants during the intervention period and none started receiving counseling services (change from baseline not statistically significant).

Feedback session transcripts confirmed the participants' overall enthusiasm for the program. One theme that emerged was the importance of the program's exclusive focus on 


\begin{tabular}{|c|c|}
\hline \multicolumn{2}{|c|}{ Table 2. Participant Characteristics $(N=22)$} \\
\hline Demographic Characteristics & $n(\%)$ \\
\hline \multicolumn{2}{|l|}{ Gender } \\
\hline Female & $21(95)$ \\
\hline \multicolumn{2}{|l|}{ Age (yrs) } \\
\hline Mean $\pm S D$ & $40.6 \pm 13.5$ \\
\hline Range & $20-66$ \\
\hline \multicolumn{2}{|l|}{ Education } \\
\hline High school or less & $6(28)$ \\
\hline Some college & $9(41)$ \\
\hline Bachelors & $3(14)$ \\
\hline Postgraduate & $4(18)$ \\
\hline \multicolumn{2}{|l|}{ Marital status } \\
\hline Married & $7(32)$ \\
\hline Divorced & $3(14)$ \\
\hline Widowed & $1(5)$ \\
\hline Single/never married & $11(50)$ \\
\hline \multicolumn{2}{|l|}{ Household income (US\$), annual } \\
\hline$<10,000$ & $5(23)$ \\
\hline $10,001-15,000$ & $6(27)$ \\
\hline $20,001-25,000$ & $1(5)$ \\
\hline $35,001-40,000$ & $3(14)$ \\
\hline $40,000-100,000$ & $7(32)$ \\
\hline$>100,000$ & 0 \\
\hline \multicolumn{2}{|l|}{ Currently has health insurance } \\
\hline Yes & $14(64)$ \\
\hline No & $8(36)$ \\
\hline \multicolumn{2}{|l|}{ Type of health insurance } \\
\hline Medicaid & $4(16)$ \\
\hline Medicare & $2(9)$ \\
\hline Private insurance & $7(32)$ \\
\hline Other & $1(5)$ \\
\hline None & $8(36)$ \\
\hline \multicolumn{2}{|l|}{ Health and healthcare characteristics } \\
\hline Body mass index $\left(\mathrm{kg} / \mathrm{m}^{2}\right)$ & 36 (range, 17-55) \\
\hline Used antidepressants in last 6 months & $7(32)$ \\
\hline Went to counseling in last 6 months & $5(23)$ \\
\hline $\begin{array}{l}\text { Used either antidepressants or counseling } \\
\text { in last } 6 \text { months }\end{array}$ & $10(45)$ \\
\hline
\end{tabular}

$S D$, standard deviation.
African Americans and its having been led by an African American peer. For example:

Well I think, that being African American-led, being with sisters, with the women that have gone through what I have gone through-I see me when I see them and I can relate. And that made me feel more comfortable regardless. I came here for one reason-to participate and to learn to be more healthy. But it really made a difference to me to be around Black women, it made the difference-all the difference in the world.

Another theme was that the program allowed participants to recognize their depression for what it actually was and find ways to address it:

I thought this was just the normal way to feel... being Black, things have always been hard.

and

When I first came to this health improvement study, I pretty much thought it was just focused solely on weight loss, exercise and eating healthy. And when I came here on the first session it seem to be very targeted on depression, so I kind of left thinking "this isn't what I signed up on, I am not depressed." The more I thought about it the more I realized that I . . . am depressed. . . I think it has opened up my eyes to really think about it-how to make myself a little bit better.

Table 3. Satisfaction/Perceived Effectiveness

\begin{tabular}{|c|c|c|}
\hline & $\begin{array}{l}\text { Very Effective } \\
\qquad(N=19) \\
n(\%)\end{array}$ & $\begin{array}{c}\text { Somewhat } \\
\text { Effective } \\
(N=19) \\
n(\%)\end{array}$ \\
\hline $\begin{array}{l}\text { Program increase awareness of } \\
\text { healthy lifestyle choices }\end{array}$ & $16(84)$ & $2(4)$ \\
\hline $\begin{array}{l}\text { Program increased awareness of } \\
\text { depression and its management }\end{array}$ & $10(53)$ & $7(27)$ \\
\hline $\begin{array}{l}\text { Program motivating to manage } \\
\text { depression }\end{array}$ & $13(68)$ & $2(11)$ \\
\hline $\begin{array}{l}\text { Program provided materials to } \\
\text { use in the future }\end{array}$ & $13(68)$ & $5(26)$ \\
\hline $\begin{array}{l}\text { Motivated to exercise more } \\
\text { frequently }\end{array}$ & $15(79)$ & $3(16)$ \\
\hline \multirow[t]{2}{*}{ Overall effectiveness } & $18(95)$ & $1(5)$ \\
\hline & Very satisfied & $\begin{array}{l}\text { Somewhat } \\
\text { satisfied }\end{array}$ \\
\hline Overall satisfaction & $16(84)$ & $3(16)$ \\
\hline
\end{tabular}


Many participants explained that feeling accountable to the group helped them achieve their goals. For example, one said:

This class was just that extra nudge that I needed to get me on track and um, to set goals, and to know that-not only I have to be accountable to that goal for myself, but to this whole group.... It really gave me [something] each week to strive for and to be able to meet with the group, that can really relate with the stuff that I am going through as well, it is really a nice change, instead of just going to, um, a nutritionist or someone else who can't really understand where I have been and where I am trying to go and where I am going to get there.

Recommended changes included bringing snacks to class, limiting to fewer participants in each group so that participants had more opportunity to talk about their experiences, and lengthening the program to more than 6 weeks.

\section{DISCUSSION}

The main purpose of this pilot intervention was to assess the acceptability and feasibility of a community-based psychoeducational wellness program aimed at increasing healthy behaviors and decreasing depressive symptoms among African Americans with symptoms of MDD. The program had excellent attendance and participants reported high levels of satisfaction. Although this uncontrolled study was not designed to rigorously assess the effectiveness of the program, pre/postintervention comparisons demonstrated large decreases in participants' depressive symptoms, as well as increases in their depression and exercise self-efficacy and selfmanagement behaviors. Understanding participants' experiences in this program may help to inform future research to eliminate depression disparities.

Many depression care programs have used psychoeducational approaches to teach self-management behaviors. ${ }^{22}$ However, little is known about how to culturally tailor such approaches to meet the needs of African Americans or how to use them in community settings. Given the low rate of recognition and treatment of depression, ${ }^{5}$ many African Americans may not even enroll in standard psychoeducational programs, let alone find them acceptable or effective. Our program's focus on exercise and wellness was very appealing to our target population. Interestingly, even though the goal to reduce depressive symptoms and the study's inclusion criteria were clearly stated in the informed consent materials, many participants only recognized their own depression partway through the intervention.

Our intervention also differed from traditional psychoeducational programs in that it openly addressed the experience of racism. When attempting to understand and eliminate healthcare disparities, one cannot overlook the important

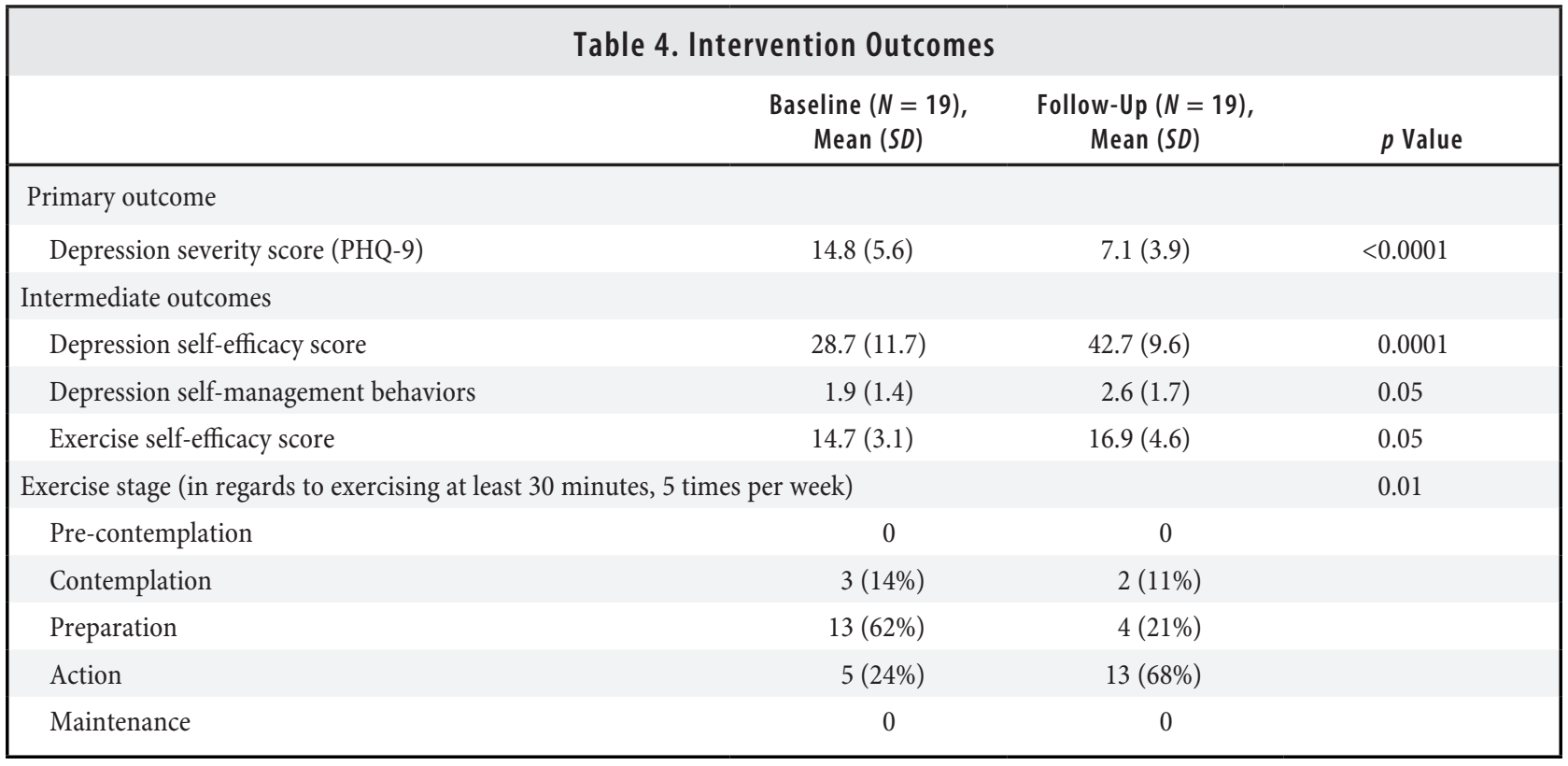

PHQ-9, Patient Health Questionnaire-9; SD, standard deviation. 
impact that racism has on the health and healthcare of racial minorities. In our own qualitative work with African American violence survivors, participants' experiences of racism dominated discussions about depression care. ${ }^{7}$ Discussions during our intervention sessions included significant attention to the experience of racism and the impact of race-related stress on depression. Participants stated these discussions were a very important component of the program and appreciated hearing about ways of dealing with the harms of racism. Inclusion of such discussions may be a particularly important component of depression care programs for African Americans.

Our study has several important limitations. As an uncontrolled trial, it is not possible to distinguish between intervention-related changes in depressive symptoms and those that would have occurred owing to the natural history of depression. However, changes in the intermediate outcomes targeted by the intervention, such as depression and exercise self-efficacy and self-management behaviors, as well as participants' own perceptions of the impact of the intervention, suggest that changes in depression severity may at least in part be related to the effects of the intervention. The study also only assessed short-term outcomes. It is unclear whether changes in participants' behavior or depressive symptoms would persist over time. There is a potential for participation bias because only $65 \%$ of invited participants took part in the intervention.

One factor that may limit the generalizability of our study is the fact that participants were already in the contemplative or preparation stage with regard to making changes in their exercise habits, given that they had already expressed interest in obtaining access to exercise facilities. Results cannot be applied to people who are not interested in increasing physical activity. Participants also all had access to exercise facilities, which may not be the case in other settings. Anecdotally, however, participants most often set activity goals that did not require the use of exercise facilities (e.g., walking in the mall). Generalizability was also limited by the fact that almost all participants were female. Men may need different recruitment approaches or a different intervention design to participate. Future research is needed on how to increase health promotion activities in men with depressive symptoms.

Despite these limitations, our study has several important implications. Our findings highlight the value of community organizations as important players in the battle to improve healthcare. They also offer promising preliminary evidence that community-based interventions with African Americans may be effective in reducing depressive symptoms by directly addressing the role of racism on health and providing education, support, and practical tools for self-management. Future research is needed to test the effectiveness of communitybased interventions to reduce depression disparities.

\section{ACKNOWLEDGMENTS}

The authors thank Nyla Moore and Angie Mejia, MS, for help with data management and transcription, and Kerri Stone-Winters, $\mathrm{PhD}$, for her recommendations regarding exercise-related measurement instruments. 
1. Young AS, Klap R, Sherbourne CD, Wells KB. The quality of care for depressive and anxiety disorders in the United States. Arch Gen Psychiatry. 2001;58(1):55-61.

2. Gonzalez HM, Vega WA, Williams DR, Tarraf W, West BT, Neighbors HW. Depression care in the United States: Too little for too few. Arch Gen Psychiatry. 2010;67(1):37-46.

3. Miranda J, Cooper LA. Disparities in care for depression among primary care patients. J Gen Intern Med. 2004;19(2):120-6.

4. Cooper LA, Gonzales JJ, Gallo JJ, Rost KM, Meredith LS, Rubenstein LV, et al. The acceptability of treatment for depression among African American, Hispanic, and white primary care patients. Medical Care. 2003;41(4):479-89.

5. Cooper-Patrick L, Powe NR, Jenckes MW, Gonzales JJ, Levine DM, Ford DE. Identification of patient attitudes and preferences regarding treatment of depression. J Gen Intern Med. 1997;12(7):431-8.

6. US Census Bureau State and County quick Facts [updated 2007 Jan 12; cited 20074 Feb 11]. Available at: http://quickfacts. census.gov/qfd/states/41/4159000.html.

7. Nicolaidis C, Timmons V, Thomas MJ, Waters AS, Wahab S, Mejia A, et al. "You don't go tell white people nothing": African American women's perspectives on the influence of violence and race on depression and depression care. Am J Public Health. 2010;100(8):1470-6.

8. McKeever C, Faddis C, Koroloff N, Henn J. Wellness Within REACH: Mind, body, and soul: a no-cost physical activity program for African Americans in Portland, Oregon, to combat cardiovascular disease. Ethnicity Dis. 2004;14(3 Suppl. 1):1-93.

9. Rethorst CD, Wipfli BM, Landers DM. The antidepressive effects of exercise: A meta-analysis of randomized trials. Sports Med. 2009;39:491-511.

10. Lorig K, Sobel D, Laurent D, Minor M. Living a healthy life with chronic conditions: Self-management of heart disease, arthritis, diabetes, asthma, bronchitis, emphysema \& others. Boulder (CO): Bull Publishing Company; 2000.

11. Kroenke K, Spitzer RL, Williams JB. The PHQ-9: Validity of a brief depression severity measure. J Gen Intern Med. 2001;16(9):606-13.

12. Spitzer RL, Williams JB, Kroenke K, Hornyak R, McMurray J. Validity and utility of the PRIME-MD Patient Health Questionnaire in assessment of 3000 obstetric-gynecologic patients: The PRIME-MD Patient Health Questionnaire ObstetricsGynecology Study. Am J Obstet Gynecol. 2000;183(3):759-69.
13. Spitzer RL, Kroenke K, Williams JB. Validation and utility of a self-report version of PRIME-MD: The PHQ primary care study. Primary Care Evaluation of Mental Disorders. Patient Health Questionnaire. JAMA. 1999;282(18):1737-44.

14. Nicolaidis C, Wahab S, Trimble J, Mejia A, Mitchell SR, Raymaker D, et al. The Interconnections Project: Development and evaluation of a community-based depression program for African American violence survivors. J Gen Intern Med. In press.

15. Gaines F, Wever R. The New Soul Food Cookbook for People with Diabetes. Alexandria (VA): American Diabetes Association; 2006.

16. Gilbody S, Richards D, Brealey S, Hewitt C. Screening for depression in medical settings with the Patient Health Questionnaire (PHQ): A diagnostic meta-analysis. J Gen Intern Med. 2007;22(11):1596-602.

17. Lowe B, Kroenke K, Herzog W, Grafe K. Measuring depression outcome with a brief self-report instrument: sensitivity to change of the Patient Health Questionnaire (PHQ-9). J Affect Disord. 2004;81(1):61-6.

18. Ludman E, Katon W, Bush T, Rutter C, Lin E, Simon G, et al. Behavioural factors associated with symptom outcomes in a primary care-based depression prevention intervention trial. Psychol Med. 2003;33(6):1061-70.

19. Nigg CR, Riebe D. The transtheoretical model: Research review of exercise behavior and older adults. In: Burbank PM, Riebe $\mathrm{D}$, editors. Promoting exercise and behavior change in older adults: Interventions with the transtheoretical model. New York: Springer; 2002. p. 147-80.

20. Lipkke S, Ziegelmann J, Schwarzer R, Velicer WF. Validity of stage assessment in the adoption and maintenance of physical activity and fruit and vegetable consumption. Health Psychol. 2009;28(2):183-93.

21. Braun V, Clarke V. Using thematic analysis in psychology. Qual Res Psychol. 2006;3:77-101.

22. Cuijpers P, Muñoz R, Clarke G, Lewinsohn P. Psychoeducational treatment and prevention of depression: The "coping with depression" course thirty years later. Clin Psychol Rev. 2009;29(5):449-58. 